\title{
O ensino de português como segunda língua para surdos: princípios teóricos e metodológicos
}

\section{Teaching Portuguese as a second language to deaf children: theoretical and methodological principles}

\author{
Maria Cristina da Cunha Pereira ${ }^{1}$
}

\begin{abstract}
RESUMO
Este trabalho discute o ensino da língua portuguesa que tem sido ministrado para alunos surdos, que proíbe o uso da língua de sinais e que se fundamenta na concepção de língua como código; a metodologia de ensino adotada e os seus efeitos na leitura e na escrita de surdos. Apresenta uma proposta que privilegia a concepção discursivo-interacionista de língua e na qual a Língua Brasileira de Sinais é considerada primeira língua dos alunos surdos. Como primeira língua, ela fornece o arcabouço para a constituição do conhecimento da Língua Portuguesa. Em outras palavras, o conhecimento de mundo e de língua constituído na língua de sinais dá a base para o aprendizado da Língua Portuguesa pelos alunos surdos. O efeito da aplicação desta proposta é analisado nas produções escritas de dois alunos surdos, do ensino fundamental, de escola bilíngue, que tem a Língua Brasileira de Sinais como primeira língua e a Língua Portuguesa, como segunda. Nas produções observa-se que os alunos apresentam vários indícios de que estão aprendendo a produzir textos em Língua Portuguesa, ainda que evidenciem muitas dificuldades, decorrentes, principalmente, do pouco conhecimento que têm da língua. Considerando que, devido à perda auditiva, é pela visão que os surdos têm acesso ao mundo, a autora sugere que os alunos surdos leiam muito, já que é desta forma que serão inseridos no funcionamento linguístico-discursivo da Língua Portuguesa.

Palavras-chave: surdez; linguagem e surdez; aprendizagem de segunda língua.
\end{abstract}

DOI: $10.1590 / 0104-4060.37236$

1 Pontifícia Universidade Católica de São Paulo. São Paulo, São Paulo, Brasil. Divisão de Educação e Reabilitação dos Distúrbios da Comunicação (DERDIC) - Rua Dra. Neyde Apparecida Sollitto, 435. CEP: 04022-040. 


\begin{abstract}
This paper discusses the way Portuguese has been taught to deaf children; that is, through the prohibition of the use of sign language and the conception of language as a code, as well as the teaching methodology and its impact on deaf children's reading and writing acquisition. It presents a proposal that places emphasis on the discursive-interactionist conception of language, in which Brazilian Sign Language is considered the deaf children's first language. As the first language, it provides the foundation which Portuguese will be built upon. In other words, the knowledge of the world and language acquired through sign language will set the tone for deaf children learn Portuguese. The effects of the practical application of this proposal are analyzed in the written productions of two junior high school deaf students, from a bilingual school, whose first language is Brazilian Sign Language and whose second language is Portuguese. By analyzing their production, it is possible to find evidences that the children have been learning to write texts, even though they still show a great deal of difficulty, especially due to their little knowledge of Portuguese. Considering that due to their hearing loss, it is through sight that they have access to the world, the author suggests that deaf children should read as much as possible because this way they will be able to immerse in the linguistic-discursive operation of the Portuguese language.
\end{abstract}

Keywords: deafness; language and deafness; learning a second language.

\title{
Introdução
}

O ensino da língua portuguesa escrita tem sido uma preocupação constante dos educadores de alunos surdos, embora a natureza da preocupação tenha sofrido mudanças ao longo do tempo.

Até recentemente, predominou, na educação de surdos, no Brasil, a abordagem oralista, segundo a qual o ensino e a aprendizagem se davam exclusivamente por meio da Língua Portuguesa na modalidade oral.

No ensino da Língua Portuguesa predominava, nessa época, a concepção de língua como código, ou seja, como um conjunto de regras que os alunos deveriam aprender para entendê-la e usá-la bem. Considerando que, diferentemente dos ouvintes, os alunos surdos chegam à escola com, no máximo, fragmentos da Língua Portuguesa, cabia ao professor conduzir os alunos no aprendizado dessa língua. A língua de sinais era proibida e os alunos tinham que recorrer à leitura orofacial e aos restos auditivos.

Embora alguns conseguissem adquirir a Língua Portuguesa, a maioria adquiria apenas fragmentos dela. As dificuldades de acesso à língua falada e a 
pouca familiaridade com a Língua Portuguesa resultaram em alunos que não entendiam o que liam e que apresentavam dificuldades acentuadas na escrita. Essas dificuldades eram tão semelhantes entre os surdos que passaram a ser atribuídas à surdez. Como consequência, eles foram considerados incapazes de compreender e de produzir textos na Língua Portuguesa.

Nos últimos anos, no entanto, têm-se observado mudanças significativas no cenário da educação de surdos, bem como no ensino da Língua Portuguesa em geral.

A aprovação do Decreto Federal n ${ }^{\circ}$ 5.626, de 22 de dezembro de 2005, que estabeleceu, entre outros assuntos, a obrigatoriedade das escolas possibilitarem aos alunos surdos uma educação bilíngue, na qual a Língua Brasileira de Sinais é a primeira língua e a Língua Portuguesa é a segunda, trouxe a língua de sinais para a educação depois de quase cem anos de proibição.

$\mathrm{O}$ uso da língua de sinais contribuiu em muito para a aprendizagem dos alunos surdos, já que, por ser visual-espacial, não oferece dificuldades para ser adquirida. Por meio dela, observou-se a ampliação do conhecimento de mundo e do conteúdo escolar e, para os surdos, filhos de pais ouvintes, abriu-se a possibilidade de aquisição de uma primeira língua. No entanto, apesar dos efeitos positivos do uso da Língua Brasileira de Sinais na ampliação do conhecimento de mundo e de língua, não se observaram resultados significativos na compreensão e uso da Língua Portuguesa, o que reforçou a ideia de que é a surdez a responsável pelas dificuldades que os surdos apresentam na língua portuguesa.

Visando contribuir para a discussão sobre o ensino da Língua Portuguesa para alunos surdos, este trabalho discute o ensino que ainda hoje é adotado em muitas escolas do Brasil, aqui chamado de ensino tradicional, e apresenta uma proposta de ensino, fundamentada na concepção discursivo-interacionista de língua e que se apoia na língua de sinais. Para ilustrar os efeitos desta proposta na aprendizagem, são analisadas produções escritas de alunos surdos do ensino fundamental de uma escola bilíngue para surdos na cidade de São Paulo.

\section{O ensino tradicional da língua portuguesa para surdos}

Por quase cem anos os surdos foram obrigados a se comunicar exclusivamente por meio da Língua Portuguesa na modalidade oral e da audição ou da leitura orofacial. Os sinais eram proibidos porque se acreditava que o seu uso pudesse prejudicar o desenvolvimento da fala. 
A grande dificuldade para compreender a fala por meio da percepção e da discriminação visual do movimento dos lábios e da face, somada ao pouco conhecimento da língua, resultou em níveis baixos de compreensão e de expressão oral (MARCHESI, 1991).

Cabe lembrar que nessa época predominava, no ensino da Língua Portuguesa, a concepção de língua como código, segundo a qual a língua é considerada um sistema de formas fonéticas, gramaticais e lexicais, independentemente de todo ato de criação individual $(\mathrm{KOCH}, 2001,2003)$. A ideia subjacente é que, conhecendo o código, o aluno poderia compreender e usar corretamente a língua.

A adoção da concepção de língua como código na educação de surdos resultou no ensino sistemático e padronizado da Língua Portuguesa, uma vez que, diferentemente dos ouvintes, a maioria dos alunos surdos, principalmente os filhos de ouvintes, chega à escola sem uma língua constituída.

Visando ao aprendizado da Língua Portuguesa, o professor iniciava com a exposição dos alunos surdos a palavras e prosseguia com a utilização destas palavras em estruturas frasais, primeiramente simples e depois cada vez mais longas e morfossintaticamente mais complexas. Por meio de cópias, ditados, exercícios de repetição e de substituição de elementos da frase, esperava-se que os alunos memorizassem as estruturas frasais trabalhadas e as usassem. Quando eram apresentados textos, os mesmos eram curtos, com vocabulário e estruturas frasais adaptados pelo professor ao nível linguístico dos alunos.

A ênfase nas palavras resultou em tendência dos alunos surdos a se aterem a cada palavra individualmente, prendendo-se, assim, ao sentido literal, dicionarizado, o que limitava a possibilidade de compreensão de texto. A preocupação com o sentido das palavras individualizadas podia ser observada também por parte dos professores, os quais, antes mesmo de verificarem o que entenderam, pediam aos alunos que sublinhassem as palavras desconhecidas, procurassem o significado das mesmas no dicionário, após o que, muitas vezes, solicitavam que os alunos escrevessem frases com as palavras pesquisadas (PEREIRA, 2011a).

$\mathrm{O}$ grande número de palavras desconhecidas nos textos provocava desânimo nos alunos surdos e, além de afastá-los da leitura, contribuía para o estabelecimento de uma representação da leitura como muito difícil e deles como incapazes de ler. Os professores, por sua vez, evitavam dar textos para os alunos lerem e, quando o faziam, geralmente eram textos adaptados e simplificados, tanto em relação ao vocabulário como às estruturas sintáticas. Com pouca leitura, o conhecimento da Língua Portuguesa não se ampliava e os alunos apresentavam cada vez mais dificuldades para ler, até se tornarem completamente desinteressados pela leitura (PEREIRA, 2011b). Embora conseguisse decodificar as palavras, a maioria dos alunos surdos não entendia o que lia. 
Em relação à escrita, a ênfase no ensino estruturado da língua e o pouco conhecimento da Língua Portuguesa resultaram no uso de frases simples e curtas, com maior número de palavras de conteúdo - nomes e verbos - e menor número de vocábulos funcionais - artigos, preposições e conjunções (MARCHESI, 1991; LANE; HOFFMEISTER; BAHAN, 1996). Além disso, observavam-se dificuldades acentuadas no uso das flexões, da concordância, e na ordenação dos vocábulos nas frases. Era como se os alunos aprendessem mecanicamente a língua, de fora para dentro, sem conseguirem fazer uma reflexão sobre o seu funcionamento.

\section{Proposta de ensino da Língua Portuguesa para surdos como segunda língua}

Na década de 1980, a insatisfação com os resultados alcançados no oralismo, o número crescente de pesquisas sobre as línguas de sinais e as pesquisas que comprovavam a superioridade no desempenho acadêmico das crianças surdas, filhas de pais surdos, resultou na entrada gradativa da língua de sinais na educação de surdos. Inicialmente a proposta foi de usar os sinais como mais um recurso para possibilitar a percepção e uso da língua oral, o que ficou conhecido como Comunicação Total.

$\mathrm{Na}$ comunicação total, a recepção da linguagem se dá por meio da leitura orofacial, da amplificação, dos sinais e do alfabeto digital, e a produção se faz por meio da fala, dos sinais e do alfabeto digital (MOORES, 1996). Na prática, os sinais foram usados concomitantemente com a fala, o que resultou no uso dos sinais na ordem da língua majoritária.

As críticas feitas à comunicação total e a reivindicação dos surdos do direito de ter reconhecida a sua língua e a sua cultura foram alguns dos fatores que determinaram a adoção da língua de sinais na educação dos surdos. A nova proposta de trabalho recebeu o nome de Bilinguismo.

O bilinguismo defende o uso de duas línguas na educação dos surdos: a língua de sinais como primeira língua, e a língua majoritária (a Língua Portuguesa, no caso dos surdos brasileiros), como segunda língua. No Brasil, o direito dos alunos surdos a uma educação que contemple as duas línguas - a Brasileira de Sinais e a Portuguesa - é garantido pelo Decreto n 5.626 , de dezembro de 2005.

Considerando que a maior parte das crianças surdas nasce em famílias ouvintes que não usam a língua de sinais, é comum que cheguem à escola com alguma forma de linguagem, criada na interação familiar. No entanto, chegam 
sem uma língua adquirida, uma vez que a Língua Portuguesa, na modalidade oral, usada pela família, lhes é inacessível e a Língua Brasileira de Sinais, que lhes é acessível, é desconhecida pela família.

Numa proposta bilíngue, a escola deve possibilitar, principalmente no caso de filhos de pais ouvintes, a aquisição da Língua Brasileira de Sinais, o que vai se dar na interação com usuários fluentes desta língua, preferencialmente surdos, os quais, ao usarem e interpretarem os movimentos e enunciados das crianças surdas na língua de sinais, as insiram no funcionamento linguístico-discursivo dessa língua.

Além de adquirirem a língua de sinais, na interação com adultos surdos, as crianças surdas terão contato com a cultura surda, o que lhes possibilitará desenvolver uma identidade positiva de surdo.

A aquisição da língua de sinais deve se dar em contexto semelhante ao vivenciado por crianças ouvintes e surdas, filhas de pais surdos, na interação com seus pais. Em outras palavras, a língua de sinais será adquirida como primeira língua.

Assim como os ouvintes, que têm a Língua Portuguesa como primeira língua e nela se baseiam no aprendizado de outras línguas, os alunos surdos vão recorrer ao seu conhecimento da Língua Brasileira de Sinais no aprendizado da Língua Portuguesa, sua segunda língua. Em outras palavras, o conhecimento de mundo e de língua elaborado na Língua Brasileira de Sinais permitirá que os alunos surdos vivenciem práticas sociais que envolvem a escrita e, deste modo, constituam o conhecimento da Língua Portuguesa (PEREIRA, 2011a).

Também nos anos 1980, por influência das ideias de Vygotsky e de Bakhtin principalmente, a língua passou a ser concebida como atividade, como lugar de interação humana, de interlocução, entendida como espaço de produção de linguagem e de constituição de sujeitos. Nesta concepção, a língua não está pronta de antemão, dada como um sistema de que o sujeito se apropria para usá-la, mas é (re)construída na atividade de linguagem (GERALDI, 1993). Produzir linguagem significa, nesta concepção, produzir discurso. O discurso, quando produzido, manifesta-se linguisticamente por meio do texto, considerado produto da atividade oral ou escrita que forma um todo significativo, qualquer que seja a sua extensão.

Como atividade discursiva, o foco é colocado no texto e não nos vocábulos e a aprendizagem deixa de ser conduzida pelo professor e passa a ser vista como resultado do processo interativo entre professores, alunos e textos. São as situações de uso da escrita que possibilitam a apreensão da convencionalidade da Língua Portuguesa. O texto, nesta concepção, é visto como lugar de interação e os interlocutores, como sujeitos ativos que, dialogicamente, nele se constroem e são construídos (GERALDI, 1993, 1996). 
Nesta concepção, a leitura não se caracteriza como decodificação de letra por letra, palavra por palavra, mas implica compreensão. A compreensão é vista como atividade interativa de produção de sentidos, que se realiza com base nos elementos linguísticos presentes no texto e na sua forma de organização, mas que requer a mobilização de um vasto conjunto de saberes e sua reconstrução no interior do evento comunicativo.

Fulgêncio e Liberato (2001) argumentam que, na leitura, o leitor não decodifica cada símbolo presente; ao contrário, ele opera com informações que já sabe. É esse conhecimento anterior sobre a língua e sobre o mundo que permite ao leitor, à medida que vai montando o sentido do texto, fazer deduções, reduzir o número de palavras viáveis em cada contexto e prever o significado, prescindindo da decodificação de cada elemento do texto.

O professor deixa de ocupar o papel principal no processo de ensino-aprendizagem, de detentor do conhecimento, para assumir o papel de parceiro, ajudando cada aluno a progredir na aprendizagem.

Assim como ocorreu na educação de ouvintes, a adoção da concepção de língua como atividade discursiva pela escola trouxe mudanças também no ensino da Língua Portuguesa para alunos surdos.

$\mathrm{O}$ ensino da língua deixou de obedecer a padrões preestabelecidos pelo professor, que passou a expor os alunos surdos à Língua Portuguesa escrita sem a preocupação de ensiná-la. A meta é que os alunos usem a língua e, ao usá-la, elaborem hipóteses sobre o seu funcionamento, sozinhos ou com a ajuda do professor. O ensino da gramática vai se dar quando os alunos estiverem usando a língua (PEREIRA, 2010).

Com base na concepção discursiva de língua, o objetivo no ensino da Língua Portuguesa para os alunos surdos, como para os alunos ouvintes, deve ser a habilidade de produzir textos e não palavras e frases, daí a importância de se trabalhar muito bem o texto, inicialmente na Língua Brasileira de Sinais. Para isso cabe ao professor traduzir os textos ou partes deles para a língua de sinais e vice-versa, bem como explicar e esclarecer aspectos sobre a construção dos textos. As explicações devem ser dadas numa perspectiva contrastiva, na qual as diferenças e as semelhanças entre a Língua Brasileira de Sinais e a Língua Portuguesa sejam elucidadas. Desta forma, os alunos vão observar como uma mesma ideia é expressa nas duas línguas. Esta prática serve de base para os alunos formularem suas hipóteses sobre o funcionamento das duas línguas.

Devido às dificuldades de acesso à linguagem oral, é por meio da visão que os alunos surdos vão adquirir a Língua Portuguesa, razão por que se lhes deve possibilitar, desde o início da escolaridade, situações de leitura. É ela que vai tornar possível o acesso à Língua Portuguesa, daí a importância de se expor os alunos surdos à leitura de textos autênticos e interessantes, de diferentes 
gêneros e tipos textuais. Desta forma, o aluno surdo poderá aprender o sistema da língua, bem como ampliar seu conhecimento letrado.

Svartholm (2003), pesquisadora sueca, propõe que a leitura de livros e de revistas seja feita com crianças desde a educação infantil porque diverte, estimula e satisfaz a curiosidade, além de ser ferramenta fundamental para a constituição do conhecimento da língua majoritária. Segundo ela, pode-se contar uma história na língua de sinais e mostrar a escrita e as imagens para que as crianças relacionem o conteúdo com o escrito, ainda que não sejam capazes de ler sozinhas. Quando começam a ler, as crianças surdas leem o texto junto com seus professores e explicam o conteúdo na língua de sinais. Os textos a serem oferecidos não são adaptados, mas fazem parte de livros comuns para crianças: contos de fadas, histórias e outros tipos de textos para crianças.

Em relação à escrita, no início do processo o professor faz papel de escriba, registrando na Língua Portuguesa o que os alunos relatam na Língua Brasileira de Sinais. Como interlocutor e escritor, o professor contribui para a elaboração do texto. Desta forma, os alunos começam a assumir com o professor a autoria do texto escrito, depois o reelaboram numa escrita individual (PEREIRA, 2011b). Trata-se de um movimento interdiscursivo, intertextual (SMOLKA, 1993). Quando começam a escrever, os alunos utilizam os conhecimentos que já têm sobre a escrita. Diferentemente das crianças que ouvem, as surdas vão se basear na visão para constituir a sua relação com a escrita.

Visando ilustrar os efeitos de uma proposta de ensino da Língua Portuguesa como segunda língua, são apresentadas e analisadas a seguir produções escritas de alunos surdos de uma escola bilíngue para surdos no Estado de São Paulo.

A escola atende exclusivamente a alunos surdos, da Educação Infantil ao $9^{\circ}$ ano do Ensino Fundamental. Conta com professores surdos e ouvintes, todos fluentes na Língua Brasileira de Sinais.

Por serem filhos de pais ouvintes, a maioria dos alunos chega à escola sem a língua de sinais e com apenas fragmentos da Língua Portuguesa.

Compatível com a abordagem bilíngue de educação de surdos, a preocupação da escola é promover a aquisição da Língua Brasileira de Sinais. Para isso os alunos são inseridos em atividades dialógicas, na interação com adultos surdos e ouvintes, e, desta forma, adquirem-na em um processo semelhante ao observado em crianças surdas, filhas de pais surdos (PEREIRA; NAKASATO, 2002).

Desde que ingressam na escola, os alunos são expostos a materiais escritos, cabendo ao professor interpretar o conteúdo na Língua Brasileira de Sinais, possibilitando, desta forma, acesso dos alunos ao conteúdo escrito em Língua Portuguesa.

Além das atividades que envolvem a leitura, as crianças são inseridas, desde o início do processo escolar, em atividades de escrita dos seus nomes, 
da professora e dos familiares, de rotinas diárias, do calendário e de pequenas produções com base em relatos e narrativas produzidos pelas crianças na Língua Brasileira de Sinais e escritos na Língua Portuguesa pela professora, na lousa. Os textos produzidos coletivamente são lidos silenciosamente, após o que a professora propõe que as crianças elaborem uma produção escrita, sozinhas ou em dupla. Depois que escrevem, é solicitado que elas interpretem o que escreveram na Língua Brasileira de Sinais e a professora registra, em Língua portuguesa, a leitura na própria folha em que foi escrita a produção da criança. Esta postura permite conhecer as hipóteses elaboradas pelas crianças. À medida que as crianças vão se familiarizando com a língua escrita, a professora passa a promover situações em que elas escrevam sem a elaboração de um texto coletivo anterior. Desde o início da escolaridade, os alunos são inseridos em textos de diferentes gêneros e tipos textuais nas duas línguas, a de sinais e a portuguesa e, na medida em que manifestam interesse, a professora explica diferenças e semelhanças entre as duas línguas.

\section{Análise e discussão dos dados}

Para ilustrar os efeitos da adoção da proposta de ensino da Língua Portuguesa como segunda língua numa concepção discursivo-interacionista e tendo a Língua Brasileira de Sinais como primeira língua, foram selecionadas para este trabalho produções escritas de dois alunos do $6^{\circ}$ ano do ensino fundamental $-\mathrm{R}$ e V.

R. é filho de pais ouvintes e entrou na escola com 3.6 anos, na educação infantil. Como a maior parte das crianças surdas, filhas de ouvintes, chegou sem nenhuma língua adquirida. Na escola passou a ser exposto à língua brasileira de sinais, na interação com professores surdos e ouvintes, adquirindo-a rapidamente e a usando na comunicação.

Também na educação infantil começou a ser inserido em atividades que envolviam a língua portuguesa e apresentou interesse em aprendê-la. $\mathrm{Na}$ época em que escreveu a produção aqui apresentada tinha 11 anos de idade.

V. é filho de pais ouvintes e tem uma irmã surda mais velha com quem se comunica por meio da língua brasileira de sinais. Chegou à escola com 9 anos, vindo do $4^{\circ}$ ano de uma escola comum. Comunica-se por meio da língua de sinais e demonstra interesse pela leitura e pela escrita. Na época em que escreveu a produção aqui apresentada estava com 12 anos de idade. 
Para este trabalho foi selecionada uma produção elaborada com base em figura, sem modelo anterior da professora.

A professora entregou a cada aluno uma folha na qual se via a figura de um gigante em pé dentro de um barco. Parece que ele está tomando banho. Na figura se veem também símbolos musicais e um homem com cara de assustado.

Abaixo da figura, havia perguntas que os alunos responderam na língua de sinais.

São elas:

1. Onde ele vivia?

2. Com quem ele vivia?

3. O que estava fazendo?

4. Você acha que ele trabalha? Qual é a profissão?

5. Quem era o homem?

No dia seguinte, a professora pediu que cada aluno inventasse uma história com base na figura.

Abaixo são apresentadas as produções de R. e de V., seguidas de uma análise na qual se considera o uso da gramática da língua portuguesa, a organização do texto e a criatividade.

Produção de R.

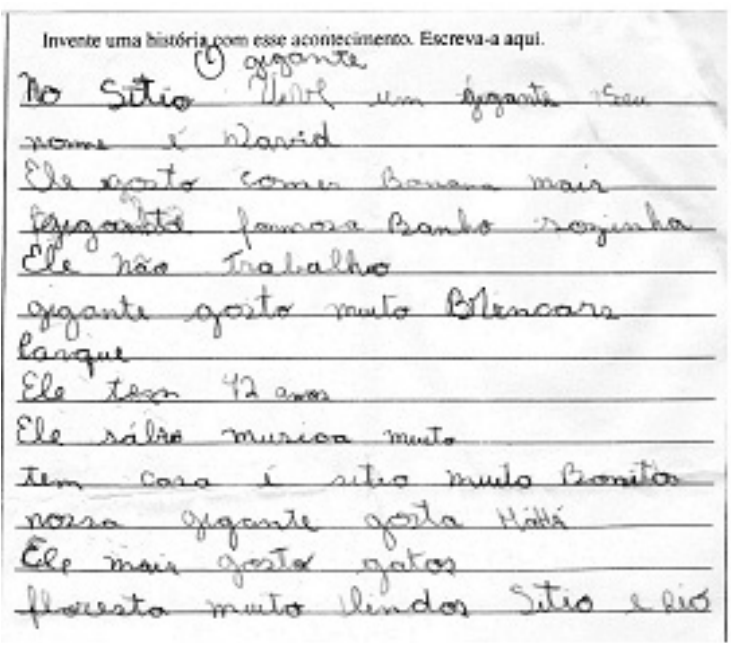

Em resposta à solicitação da professora, R. produz um texto bem organizado. Nele aparece o título, o qual, por estar escrito fora da linha, dá a impressão de ter sido inserido depois. Em seu texto, R. intercala descrição do personagem (gigante) com relato sobre suas preferências e hábitos. 
Com relação ao uso da língua portuguesa, o aluno faz uso de orações curtas e morfossintaticamente simples, consistindo, na maior parte das vezes, de sujeito - verbo e objeto. A conjunção aditiva, que aparece duas vezes no texto, não articula orações, mas soma elementos. Em suas orações predominam substantivos e verbos, embora se observem também pronomes pessoais, adjetivos e advérbios. Os verbos estão conjugados no presente e, na maioria das vezes, estão flexionados na primeira pessoa do singular, sendo que o sujeito das orações exige a terceira pessoa.

Quanto à criatividade, na tarefa de produzir um texto, o aluno recorre ao seu conhecimento de mundo, como, por exemplo, que o gigante mora num sítio e que gosta de brincar no parque.

Produção de V.

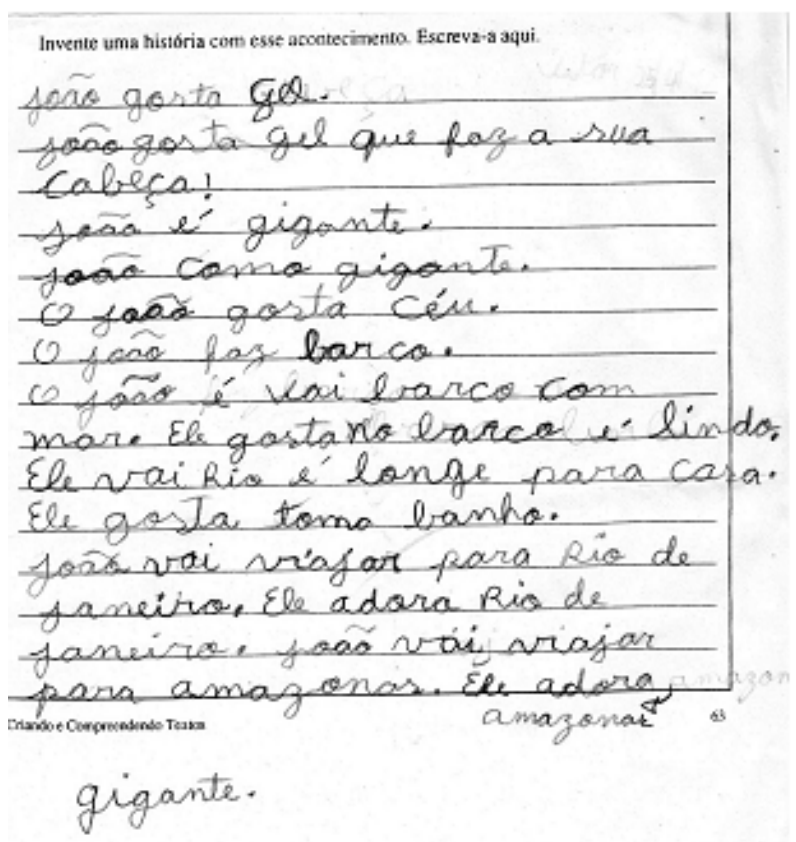

Como R., também V. produz um texto bem organizado em relação às ideias. Descreve o que vê, o gigante em um barco, no mar, e relata preferências do personagem. Faz uso de orações curtas, simples, que se caracterizam, na maior parte das vezes, pela estrutura sujeito - verbo - objeto. Em alguns trechos se observam tentativas de elaboração de orações mais complexas, nas quais se constata o uso 
do pronome relativo, como em: "João gosta gel que faz a sua cabeça”. Assim, como se observou na produção de R., os verbos são conjugados no presente, mas, diferentemente de R., estão flexionados na $3^{a}$ pessoa do singular, concordando com o sujeito das orações. Quanto às categorias gramaticais, além de substantivos, verbos, pronomes e adjetivos, o aluno apresenta algumas preposições, como em (na forma no) e para, referindo-se à direção do movimento.

Embora o aluno faça uso de muitos recursos da gramática da língua portuguesa, as dificuldades de uso destes elementos resultam em trechos de difícil compreensão pelo leitor. Por outro lado, pode indicar que ele está elaborando hipóteses sobre o funcionamento da língua portuguesa.

No que diz respeito à criatividade, V. parece recorrer ao seu conhecimento de mundo, quando fala sobre o desejo do gigante de ir ao Rio de Janeiro e ao Amazonas. Cabe lembrar também que, na época, o aluno estava usando gel nos cabelos, o que pode explicar ele ter escrito que o gigante gostava de gel.

Nas duas produções é possível evidenciar indícios de que os alunos estão aprendendo a língua portuguesa. Ambos são usuários da língua de sinais e, portanto, é de se esperar que o conhecimento de mundo que eles revelam tenha sido adquirido na língua de sinais. Quanto ao conhecimento da língua portuguesa, considerando que a perda auditiva dificulta ou mesmo impede o acesso à linguagem oral, e, considerando, ainda, que nenhum dos dois alunos faz uso desta modalidade oral da língua portuguesa, é possível afirmar que o que eles sabem foi constituído na interação com a língua portuguesa escrita, interpretada na língua de sinais. Cabe resaltar que os alunos são estimulados a ler na escola e a levar livros e revistas para casa.

Ainda que os dois alunos revelem estar aprendendo a língua portuguesa, as produções que apresentam no $6^{\circ}$ ano do ensino fundamental são muito simples, tanto no vocabulário quanto nas estruturas sintáticas, quando comparadas com as de alunos ouvintes de mesmo nível de escolaridade. Neste ponto, cabe lembrar que, por não contarem com uma língua quando chegam à escola, os alunos surdos geralmente apresentam uma defasagem muito grande se comparados aos alunos ouvintes que chegam à escola com a língua portuguesa.

\section{Conclusão}

O objetivo deste trabalho foi mostrar que não é a surdez a responsável pelo baixo desempenho dos alunos surdos na aprendizagem da língua portuguesa, mas a forma como esta língua tem sido ensinada nas escolas. 
Por muitos anos (e até hoje em muitos lugares), adotou-se, no ensino da língua portuguesa para os alunos surdos, assim como para os aprendizes de segunda língua, a concepção de língua como código. Nesta concepção o foco era colocado no aprendizado das palavras e das estruturas frasais, ficando o texto em segundo plano. Para isso, os alunos eram submetidos a cópias e exercícios que visavam ao aprendizado da gramática da língua portuguesa. $\mathrm{O}$ resultado foi, em grande parte das vezes, alunos que copiavam sem compreensão e que faziam os exercícios mecanicamente, sem entenderem o funcionamento da língua. Ainda em relação à compreensão, a ênfase nas palavras respondeu por uma preocupação grande com o sentido literal das palavras, o que muitas vezes prejudicava a compreensão.

A adoção da abordagem oralista, na qual os sinais são proibidos, dificultava ainda mais o aprendizado da língua portuguesa, uma vez que os alunos surdos deveriam recorrer à leitura dos movimentos dos lábios e dos músculos faciais do falante, o que não é uma tarefa fácil, considerando as semelhanças entre os fonemas e a não visibilidade dos sons produzidos na parte posterior da boca, por exemplo. Marchesi (1991), entre outros autores, considera que a leitura labial (como ele chama) é uma tarefa difícil, lenta e depende, principalmente, do conhecimento prévio que se tenha da língua que está sendo usada.

A oficialização da língua brasileira de sinais e a regulamentação, pelo Decreto 5.626, de 2005, do direito dos alunos surdos de terem uma educação bilíngue, na qual a língua brasileira de sinais é a primeira e a língua portuguesa, preferencialmente na modalidade escrita, é a segunda, possibilitou a aquisição da língua de sinais, que, por ser visual-espacial, não oferece dificuldade para os surdos. A aquisição da língua brasileira de sinais ampliou as possibilidades de compreensão do mundo pelos alunos, assim como permitiu aos alunos trocarem experiências e discutirem diferentes assuntos. No entanto, embora o conhecimento da língua de sinais aumentasse visivelmente, o desempenho dos alunos na língua portuguesa se mantém ruim.

A adoção de uma concepção de língua que valorize o texto e não as palavras isoladas, a compreensão na leitura e não apenas a decodificação sem sentido pode, como se procurou mostrar neste trabalho, promover o aprendizado da língua portuguesa.

A análise de produções escritas de dois alunos surdos, do $6^{\circ}$ ano do ensino fundamental de uma escola bilíngue para surdos, em São Paulo, evidenciou que, se expostos a textos na língua portuguesa, interpretados na língua de sinais, os alunos surdos podem atribuir sentido ao que leem e produzir sentido ao que escrevem. Para isso, devem contar com o conhecimento de mundo e de língua portuguesa. Na ampliação do conhecimento de mundo, a língua de sinais tem papel fundamental, na medida em que permite a discussão de qualquer assunto 
numa língua que é acessível aos alunos. A constituição e ampliação do conhecimento da língua portuguesa vai se dar, prioritariamente, por meio da leitura, uma vez que é pela visão, e não pela audição, que os alunos surdos poderão elaborar suas hipóteses sobre o funcionamento linguístico-discursivo da língua portuguesa.

\section{REFERÊNCIAS}

BRASIL. Decreto $n^{\circ} 5.626$, de 22 de dezembro de 2005. Regulamenta a Lei no 10.436 , de 24 de abril de 2002, que dispõe sobre a Língua Brasileira de Sinais - Libras, e o art. 18 da Lei n ${ }^{\circ}$ 10.098, de 19 de dezembro de 2000. Diário Oficial da União, Brasília, DF, 23 dez. 2005. Disponível em: <http://www.planalto.gov.br/ccivil_03/_ato2004-2006/2005/ decreto/d5626.htm>.

FULGÊNCIO, L.; LIBERATO, Y. A leitura na escola. 2. ed. São Paulo: Contexto, 2001. GERALDI, J. W. Portos de Passagem. 2. ed. São Paulo: Martins Fontes, 1993.

. Linguagem e ensino: exercícios de militância e divulgação. Campinas, SP: Mercado de Letras, 1996.

KOCH, I. V. O texto e a construção dos sentidos. 5. ed. São Paulo: Contexto, 2001.

. Desvendando os segredos do texto. 2. ed. São Paulo: Cortez, 2003.

LANE, H.; HOFFMEISTER, R.; BAHAN, B. A journey into the Deaf-World. California: DawnSign Press, 1996.

MARCHESI, A. El desarrollo cognitivo y lingüistico de los niños sordos. Madrid: Alianza Editorial, 1991.

MOORES, D. F. Educating the deaf: psychology, principles and practices. 4. ed. U.S.A.: Houghton Mifflin Company, 1996.

PEREIRA, M. C. C.; NAKASATO, R. A língua de Sinais Brasileira em funcionamento: reflexão sobre o uso da língua de Sinais Brasileira no discurso narrativo de criança surda. Revista Intercâmbio, São Paulo: Pontifícia Universidade Católica, v. XI. p. 69-76, 2002.

PEREIRA, M. C. C. A constituição de sentidos na leitura e na escrita por alunos surdos. In: MENDES, E. G.; ALMEIDA, M. A. (Org.). Das margens ao centro: perspectivas para as políticas e práticas educacionais no contexto da educação especial inclusiva. Araraquara, SP: Junqueira \& Marins, 2010, p. 325-332. 
. Aquisição da língua portuguesa escrita por crianças surdas. Anais do Simpósio Internacional de Ensino da Lingua Portuguesa - SIELP. Volume 1, número 1. Uberlândia, MG: EDUFU, 2011a, p. 610-617.

. Reflexões sobre a escrita de alunos surdos expostos à abordagem bilíngue de educação. In: FARIA, E. M. de B.; CAVALCANTE, M. C. B. (Org.). Desafios para uma nova escola: um olhar sobre o processo ensino-aprendizagem de surdos. João Pessoa, PB: Editora da UFPB, 2011b, p. 49-64.

SMOLKA, A. L. B. A criança na fase inicial da escrita: A alfabetização como processo discursivo. 6. ed. São Paulo: Cortez, 1993. (Coleção Passando a Limpo).

SVARTHOLM, K. Como leerles a los sordos? Disponível em: <www.sitiodesordos.com. ar>. 2003. Acesso em: 10/10/2008.

Texto recebido em 25 de julho de 2014 .

Texto aprovado em 07 de agosto de 2014. 
